\title{
Knowledge, Attitude and Practices Among Mothers Towards Insecticide-Treated Nets in Abuharira Village -Um Remta Locality- The White Nile State -2015
}

\author{
Tayseir T. M. Masaad², Yousif M. Elmosaad ${ }^{1}$, Abd Elbasit Elawad Mohammed ${ }^{2}$, \\ Ahmed Elnadif Elmanssury ${ }^{1}$, Mahmoud Jaber ${ }^{1}$, Mustafa M. Mustafa ${ }^{1}$, Husam Edrees ${ }^{1,3}$ \\ ${ }^{1}$ Department of Public Health, Faculty of Public Health and Health Informatics, Qassim University, Albukayriyah, KSA \\ ${ }^{2}$ Department of Health Education, Faculty of Public and Environmental Health, University of Khartoum, Khartoum, Sudan \\ ${ }^{3}$ Department of Physiology, Faculty of Medicine, Zagazig University, Zagazig, Egypt
}

\section{Email address:}

Taysertag@hotmail.com (T. T. M. Masaad), Yousifm_34@hotmail.com (Y. M. Elmosaad), healthabdalbasit@gmail.com (A. E. E. Mohammed), elnadif269@yahoo.com (A. E. Elmanssury), mahmoud.jaber73@yahoo.com (M. Jaber), mustafanag_1971@yahoo.com (M. M. Mustafa), husam_qu@hotmail.com (H. Edrees)

\section{To cite this article:}

Tayseir T. M. Masaad, Yousif M. Elmosaad, Abd Elbasit Elawad Mohammed, Ahmed Elnadif Elmanssury, Mahmoud Jaber, Mustafa M. Mustafa, Husam Edrees. Knowledge, Attitude and Practices Among Mothers Towards Insecticide-Treated Nets in Abuharira Village -Um Remta Locality- The White Nile State -2015. Science Journal of Clinical Medicine. Vol. 6, No. 2, 2017, pp. 24-31.

doi: $10.11648 /$ j.sjcm.20170602.11

Received: March 13, 2017; Accepted: March 24, 2017; Published: April 1, 2017

\begin{abstract}
Malaria is the most prevalent parasitic endemic disease in North Sudan, $75 \%$ of the total population is at risk. WHO recommends the use of insecticide-treated nets (ITNs) an effective malaria control strategy. This study was aimed to assess the knowledge, attitudes and practices of mother's about Insecticide-Treated Nets as one of the preventive measures against malaria. This is a descriptive community based study of (295) mothers living in Abo Harira village in North Sudan. The pre-tested structured questionnaire was used for data collection. Multivariate logistic regression was used to study association between the dependent and independent variables, using Spss version 20. The study showed that more than half (55.9\%) of mothers had good knowledge regarding ITNs, In spite of good knowledge about ITNs, (66.8 \%) of mothers still had negative attitude and only (27.8\%) reported always sleeping under it. Multivariate analysis suggested that mothers aged $\leq 31$ years were more likely to have good knowledge about ITNs compared with mother with age $\geq 32$ years [OR; 0.5174 (95\% CI: 0.2974-0.9001)]. Similarly, mothers who had formal education were more likely to have knowledge about ITNs, two time higher than those with informal education [OR; 2.2 (95\% CI: 1.274-3.788)]. We observed that mothers with age $\leq 31$ years had positive attitudes towards ITNs [OR=0.461; $95 \% \mathrm{CI}=(0.2578-0.8232)]$. In addition, mothers with formal education were more likely to have positive attitude toward ITNs two time higher than those with informal education [OR; 1.99 (95\% CI: 1.11823.5731)]. Only association between income and practice is evident. Higher income group is more likely to practice preventive activities two time higher than those with low income group [OR; 1.69 (95\% CI: 1.0158-2.8214)]. We Conclude that the attitude and practice of mothers to ITNs in this study was poor. Multivariate analysis revealed that knowledge of mothers about ITNs has significant association with age and education, also illustrate that mothers attitude towards ITNs has significant association with age, mother's work, education and monthly income. Therefore, Education System and the Malaria Control Programme in North Sudan should work closely, especially on malaria education for behaviour change as a key element for increasing utilization of ITNs.
\end{abstract}

Keywords: Malaria, Insect Treated Nets (ITNs), Mothers, Knowledge, Attitudes, Practices 


\section{Introduction}

Worldwide, an estimated half of world populations are at risk of malaria [1]. Malaria is endemic in Africa, with an estimated $80 \%$ of cases are almost exclusively due to $\mathrm{P}$. falciparum [2], and $91 \%$ of deaths occurred, amongst children and pregnant women. Children under-five years of age most at risk of infection and adverse outcomes [1], [3].

In Northern Sudan, malaria is a major public health problem [4]. It is a leading cause of morbidity and mortality, nearly $75 \%$ of the total population is at risk of malaria, $30 \%$ of inpatient admissions and $16 \%$ of hospital deaths are attributed to malaria [5]. Overall parasite prevalence has doubled in 2012 compared to 2009 (increased from $1.8 \%$ in 2009 to $3.3 \%$ in 2012) [4]. Interventions strategies to control malaria in North Sudan the use of insecticide treated net is one of them, between 2012 and 2014 national malaria control programme distribute sufficient ITNs to protect $54 \%$ of highrisk populations[2]. Even though, the Abuja declaration targets agreed upon by African heads of state in 2000 aims to provide at least $80 \%$ of pregnant women with ITNs by the year 2005 , only $54 \%$ of high-risk populations presently make use of an ITN in Sudan which hindered the effectiveness of ITNs.

Among other preventive interventions, WHO recommends the use of insecticide-treated nets (ITNs), particularly longlasting insecticidal nets, which have been shown, reduce malaria episodes among children $<5$ years of age by approximately $50 \%$ and all-cause mortality by $17 \%$ [6] Universal coverage with ITNs is defined as use by $>80 \%$ of individuals in populations at risk [7].

Moreover regarding the effectiveness of ITNs a number of studies have confirmed that the use of insecticide-treated nets (ITNs) reducing clinical malaria episodes by 48 to $50 \%$ and malaria-related morbidity mortality [5], [8]. A $25 \%$ reduction in all-cause mortality for children one to nine years of age was detected during the first year of the Gambian National Bednet Program [9]. In Kenya, 33\% reduction in mortality and also were found that $44 \%$ reduction in hospital admissions for severe malaria and reduce malaria transmission by at least $60 \%$ and child deaths by $20 \%[10]$.

These findings approved that ITNs are an effective malaria control strategy, even though, there have been many challenges to ITNs coverage, misconceptions concerning ITNs utilization and poor knowledge when trying to implement large-scale ITN programs.

Um Remta Locality is one of the White Nile State localities. This state is known as malarious zone with recorded cases of malaria throughout the year [31]. The major malaria vector control strategy is the usage of Insecticide Treated Nets. However, the monitoring and evaluation about usage of ITNs was not adequate. Also there were no recent data on the knowledge, attitudes and practice (KAP) of mothers about use of ITNs, Therefore, this study was conducted to assess the level of knowledge, attitudes and practices among mothers about Insecticide-Treated Nets as one of the preventive measures against malaria.

\section{Materials and Methods}

\subsection{Study Design}

A descriptive community based study was conducted in Um Remta locality - White Nile State with an objective, to assess the level of knowledge, attitudes and practices among mothers about Insecticide-Treated Nets as one of preventive measures against malaria.

\subsection{Study Area}

The study was conducted in Abo Harira village, Um Remta, which is one of the eight localities that form White Nile State administrative system. It's located at West of White Nile state at latitudes $14.30 \circ \mathrm{N}$, and longitudes $31.35^{\circ} \mathrm{E}$. It is surrounded by forests from West and North Side. Um Remta covers an area of $45,412 \mathrm{~km}^{2}$ with a total population of 118919, of which 65405 are female.

The heavy rainy season in the area is between June and September, during which crop cultivation takes place. The total annual rainfall ranges between (900-100 mm). The climate in general is hot with relative humidity varies from $50-70 \%$. The mean maximum temperature is $40^{\circ} \mathrm{C}$, occurred during summer season; while the mean minimum temperature is $18.0^{\circ} \mathrm{C}$ occurred during winter seasons. The common source of water supply in the area is River Nile and arteizian wells. The locality has 4 hospitals, 12 health centers also has 18 higher secondary schools and 52 primary schools. The main malaria prevention and control strategies being undertaken in the study area include ITNs, IRS, use of pesticides to control larvae, adult mosquitoes, environmental intervention and case management.

\subsection{Study Population}

The study population included all the mothers living in Abo Harira village, Um Remta locality- White Nile State, who were freely provided by insecticide treated nets (ITN).

\subsection{Sampling Technique}

The study areas were purposively selected to represent the rains malarias areas of the Um Remta locality, White Nile state. It's characterized by year round transmission with seasonal peaks following the heavy rains. Abo Harira village was randomly selected from the list of Um Remta locality villages. All mothers (295) living in Abo harrira village were freely provided with ITN were considered as sample size.

\subsection{Data Collection}

A close-ended, pre-tested and structured questionnaire was administered by interview method to all mothers visited at their homes. The questionnaire consist of four sections: Socio-demographic data includes age, educational level of mothers, monthly income family size and occupation. The variables include knowledge, attitude towards insecticidetreated nets and practice of preventives measures likes 
ownership and use of insecticide-treated bed nets. The data was collected by public health officers during January 2015.

Determination of knowledge, attitude and practice regarding insecticide-treated nets:

Based on the previous studies conducted in different part of malaria endemic areas the average mean of overall knowledge, attitude and practice score has been considered as the cutoff point [3], [27], [28], [30].

Mothers knowledge assessment: A composite variable was generate an overall knowledge score was calculated by adding up the scores for each mothers across all (11) questions and the total score was (15), zero point was given for an incorrect answer and one point was given for correct answer. Those whose score are equal to mean (8.2) or above were taken as having good knowledge while those with score of less than the mean $(<8.2)$ were considered as having poor knowledge about insecticidetreated bed nets.

Mothers attitude assessment: An overall attitude score was determined for each participants by adding up the scores across the six attitude questions and the total score was (6). Participants with score of greater than or equal to the mean score (3.04) were considered as having positive attitude whereas those with score of less than the mean score were taken as having negative attitude towards ITNs.

Mothers practices assessment: Was assessed based on the participants answers to the practices questions, if mothers always performed a good practice i.e., owning and sleeping under a mosquito net, she was given a score of one points, if on the other hand, she never performed a good practice, she was given a score of zero. An overall practices score was calculated by adding up the scores across the (7) ITNs practices questions and the total score was (7) mothers with score of greater than or equal to the mean score (3.2) were considered as having good practice while those with score of less than the mean score were taken as having poor practice in relation to ITNs.

\subsection{Data Analysis}

The data obtained from the participants through research tool was analyzed. Depending on the types of the variables, descriptive statistics were used to tabulate and describe the data, and inferential statistics was used to examine association between variables. While Odds ratio (OR) with $95 \%$ confidence interval was calculated to study check statistical association between the dependent and independent variables using the binary logistic regression. The data was analyzed through Statistical software Package for Social Sciences (SPSS) version 20. The tests were carried out at $95 \%$ confidence interval, p-values less than 0.05 were considered significant.

\subsection{Ethical Considerations}

The study was reviewed and approved by the Ethical Committee of the Medical and Health Studies Board at
University of Khartoum. Moreover, during training of the interviewers, emphasis was placed on the importance of obtaining informed oral consent before every session of the interview.

\section{Results}

\subsection{Socio-demographic Characteristics of Respondents}

Table 1. Socio-demographic characteristics of respondents ( $n=295)$.

\begin{tabular}{lll}
\hline Demographic characteristic & Count & Percent \\
\hline Age in year & & \\
$18-31$ & 145 & 49.2 \\
$32-45$ & 150 & 50.8 \\
Mother work & & \\
Yes & 48 & 16.3 \\
No & 247 & 83.7 \\
Fathers work & & \\
Yes & 252 & 85.4 \\
No & 43 & 14.6 \\
Family Size & & \\
up to 6 members & 200 & 67.8 \\
$>6$ members & 95 & 32.2 \\
Educational level of the mother & & \\
Informal & 90 & 30.5 \\
Formal & 205 & 69.5 \\
Monthly income & & \\
up to 450 SDG & 152 & 51.5 \\
$451-1450$ SDG & 143 & 48.5 \\
\hline
\end{tabular}

Two hundred ninety five (295) mothers participated in the study and were interviewed during the period of study. Their mean age was $30.8 \pm 12.1$ years, with about $50.8 \%$ aged between 32 and 45 years. However majority of the mothers had formal education (69.3\%). Number of children alive ranged between up to 6 members and more than 6 members. Related to the occupational status of the participants, majority of mothers non-employed $(83.7 \%)$, while $(85.4 \%)$ of the household were engaged in work and (51.5\%) of those household had monthly income $<450$ Sudan Pound. (Table1).

\subsection{Mothers' Knowledge, Attitude and Practice Regarding ITNS}

Table 2. Mothers' knowledge, attitude and practice regarding ITNs.

\begin{tabular}{llll}
\hline & & Yes & \\
\hline Knowledge of nets & Count & Percent \\
\hline 1 & Familiar with mosquito nets & 291 & 98.6 \\
2 & ITNS prevent mosquito bites & 294 & 99.7 \\
3 & Know the types of mosquito nets & 278 & 94.2 \\
& know the types of ITN & 167 & 56.6 \\
4 & Long-lasting insecticidal net & 20 & 6.8 \\
& Conventionally treated nets & 20 & 6.8 \\
5 & All types & 127 & 43.1 \\
6 & Know the benefits of ITN & 167 & 78.4 \\
7 & know how to save the ITN & 66 & 39.5 \\
8 & Know that ITN needs re-treatment & 163 & 55.3 \\
9 & Know that when ITN will be re-treated & 124 & 42.0 \\
10 & know way to treat the ITN & 116 & 39.3 \\
Beliefs of Mothers toward ITN & 53 & 18.0 \\
1 & Prefer a certain type of mosquito nets & & \\
2 & Prefer a certain type of ITN & 189 & 64.1 \\
\hline
\end{tabular}




\begin{tabular}{llll}
\hline \multicolumn{3}{l}{ Yes } \\
\hline Knowledge of nets & Count & Percent \\
\hline 3 & Belief that impregnated mosquito net its safe & 51 & 17.3 \\
4 & Prefer a certain color of ITN & 198 & 67.1 \\
5 & Agreed that using an ITN the best way to & 80 & 27.1 \\
$\quad$ prevent malaria infection & Perceived that malaria life threatening diseases & 254 & 86.1 \\
Mothers behaviour & & \\
1 & ITNs owned by household & 196 & 66.4 \\
2 & Usually sleeps under a net & 82 & 27.8 \\
3 & Washing ITN periodically & 193 & 65.4 \\
4 & All family members use ITN & 196 & 66.4 \\
5 & Hang up the net before sun set until dawn & 121 & 40.0 \\
6 & Use ITN all over the year & 25 & 12.5 \\
7 & Re-treat the net & 87 & 29.5 \\
\hline
\end{tabular}

Knowledge about ITNs was considerably higher among mothers. Table 2 revealed that majority of the mothers (98.6\%) were familiar with mosquito nets, $(99.7 \%)$ of mothers knew that mosquito bites can be prevented by ITNS, $(94.2 \%)$ of mothers recognized all types of mosquito nets and $(56.6 \%)$ of mothers specifically knew all the types of ITN like Long-lasting insecticidal net and conventionally treated nets. However (78.4\%) interviewees indicated that they know the benefits of ITN, and (39.5\%) the mothers knew that ITN kills or repel mosquitoes. Mothers knowledge to keep ITN effective was insufficient. The result showed that $(55.3 \%)$ of mothers knew how to save the ITN, (39.3) knew that when ITN needed to be re-treated, (18.0) knew ways to treat the ITN and only $42.0 \%$ of them had the knowledge that ITN needs re-treatment.

Beliefs about ITN among study participants is low, only $27.1 \%$ of mothers agreed that using an ITN is the best way to prevent malaria infection, $26.1 \%$ of mothers preferred a certain type of ITN. Likewise, $17.3 \%$ of mothers responded they were belief that impregnated mosquito net its safe. While $(86.1 \%)$ of mothers perceived that malaria is life threatening diseases.

Regarding ITNs Utilization. The results revealed that $(66.0 \%)$ of mothers reported that they owned an ITN. Among the 196 mothers owned an ITN only $82(27.8 \%)$ reported always sleeping under it, whereas $12.5 \%$ of mothers used ITN all over the year.

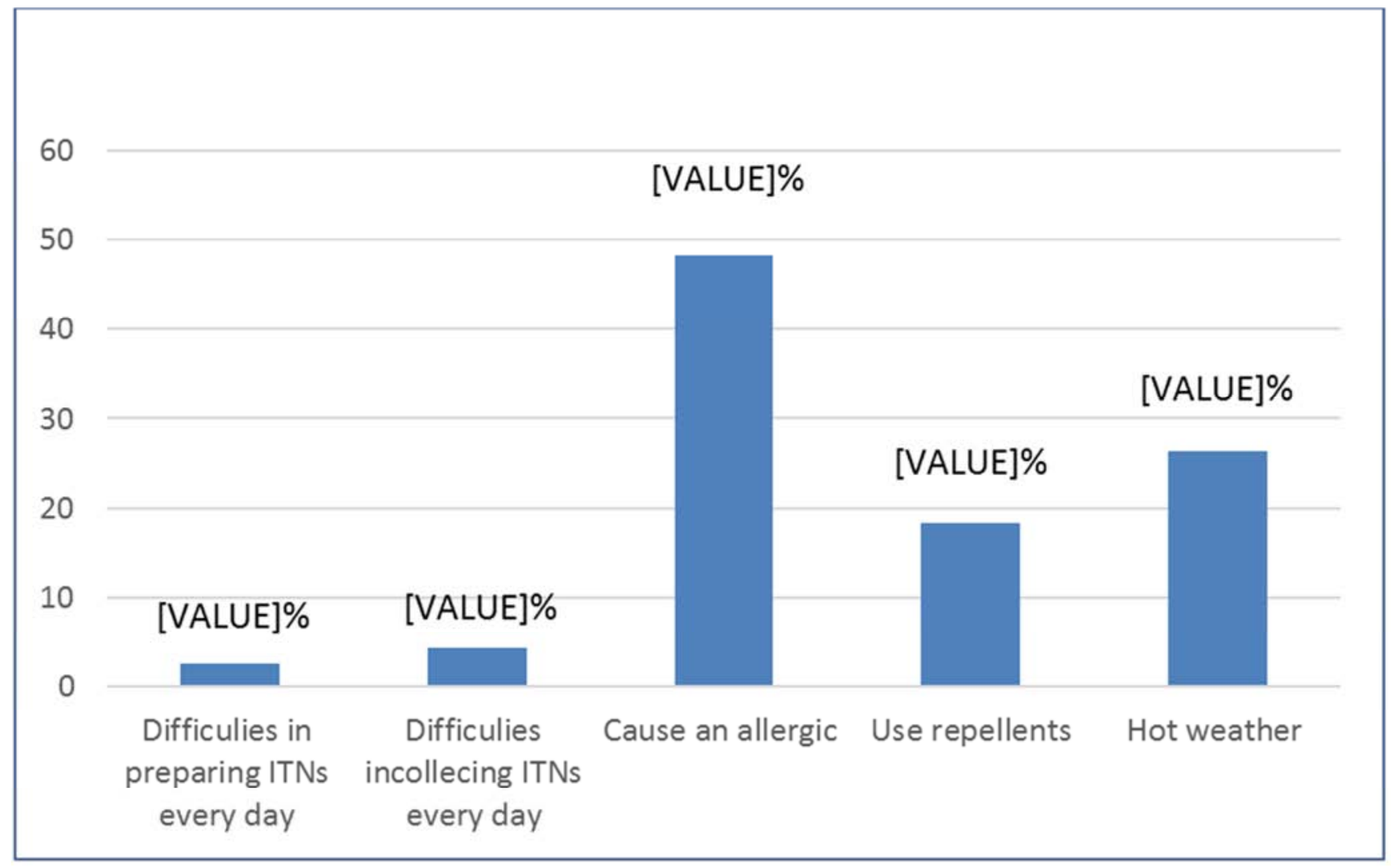

Figure 1. Respondents reasons not using ITN s.

The main reason that they were not using ITNs was ITN cause allergic(48.2\%), ITN caused thermal stress $(26.3 \%)$, using repellents $(18.4 \%)$, and difficulties in collecting and hanging ITNs every day $(4.4 \%),(2.6 \%)$ respectively. (Figure 1$)$ 


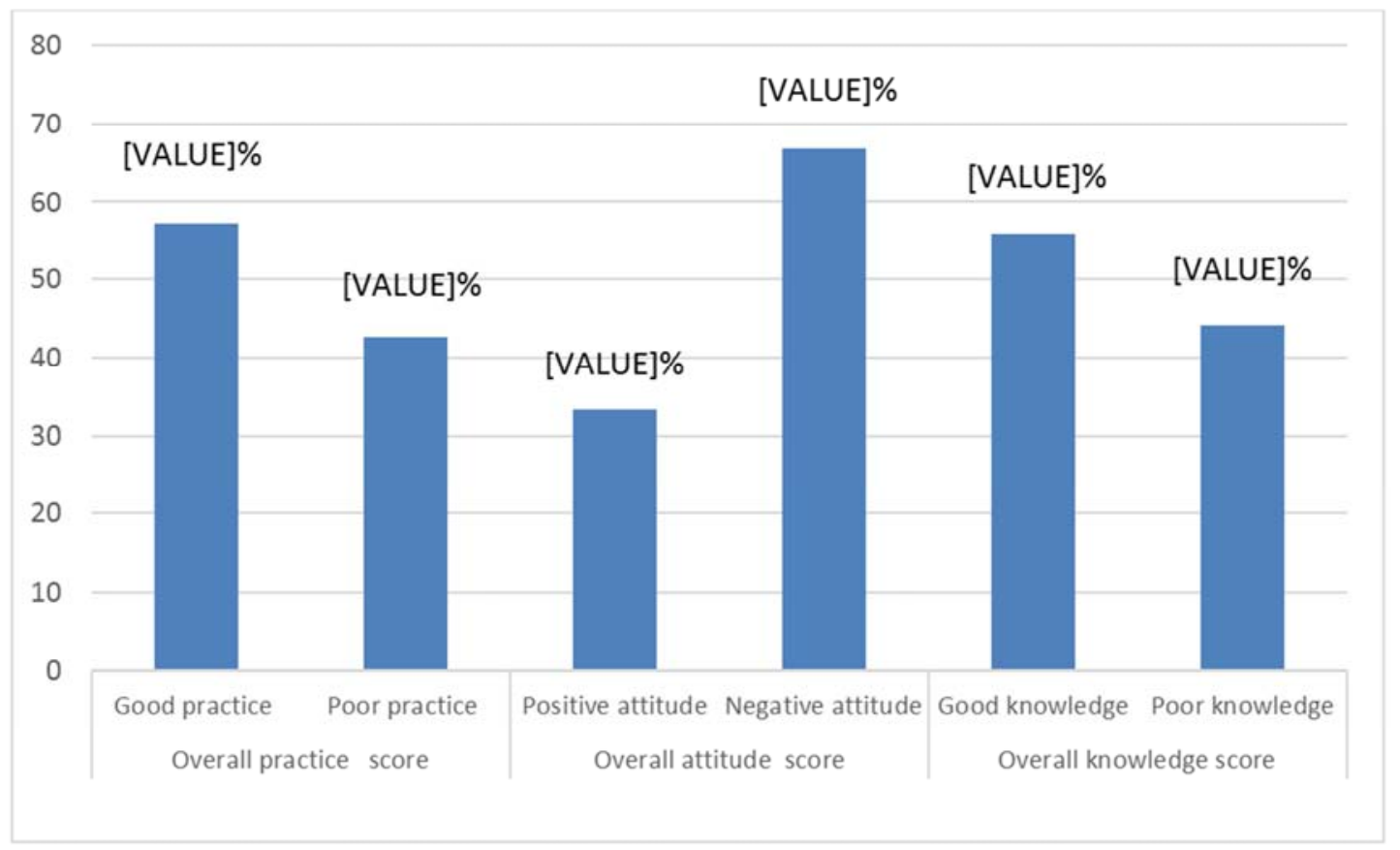

Figure 2. Overall score of mother's knowledge, attitudes and practice about ITNs.

Overall Knowledge about ITN was calculated by adding up the score for each other across all (11) questions and the total score was (15). Poor Knowledge with score of less than the mean $(<8.2)$ and Good Knowledge with the score equal to mean $(8.2)$ or above.

Overall attitude score was determined for each participants by adding up the scores across the (6) attitude questions and the total score was (6). Participants with score of greater than or equal to the mean score (3.04) were considered as having positive attitude whereas those with score of less than the mean score were taken as having negative attitude towards ITNs.

Overall practices score was calculated by adding up the scores across the (7) ITNs practices questions and the total score was (7) mothers with score of greater than or equal to the mean score (3.2) were considered as having good practice while those with score of less than the mean score were taken as having poor practice in relation to ITNs

Figure 2. Showed that overall level of knowledge of mothers about ITNs was categorized as good or poor. Consequently, almost more than half (55.9\%) of them had good knowledge regarding ITNs, while the remaining $44.1 \%$ of the mothers possessed poor knowledge. With regard to the attitude more than half of the mothers $(66.8 \%)$ had negative attitude towards ITNs, while the remaining $(33.2 \%)$ of the mother's possessed positive attitudes. However mothers who owned ITNs (57.3\%) had good practice while $42.7 \%$ mothers had poor practice.

\subsection{Association Between Socio-demographic Variables and Mother's Knowledge Attitude and Practice About ITNs}

Table 3. Association between socio-demographic variables and mothers knowledge about ITNs.

\begin{tabular}{|c|c|c|c|c|c|c|c|c|}
\hline \multirow{2}{*}{ Variables } & \multirow{2}{*}{ B } & \multirow{2}{*}{ S.E. } & \multirow{2}{*}{ Wald } & \multirow{2}{*}{ df } & \multirow{2}{*}{ Sig. } & \multirow{2}{*}{$\operatorname{Exp}(B)$} & \multicolumn{2}{|c|}{ 95.0\% C.I. for $\operatorname{EXP}(B)$} \\
\hline & & & & & & & Lower & Upper \\
\hline \multicolumn{9}{|l|}{ Age } \\
\hline 31 years or less & 1 & & & & & & & \\
\hline More than 32 years & -0.6590 & 0.2825 & 5.4406 & 1 & 0.0197 & 0.5174 & 0.2974 & 0.9001 \\
\hline \multicolumn{9}{|l|}{ Mother work } \\
\hline housewife & 1.0000 & & & & & & & \\
\hline yes & -0.5636 & 0.3529 & 2.5505 & 1 & 0.1103 & 0.5691 & 0.2850 & 1.1367 \\
\hline \multicolumn{9}{|l|}{ Household work } \\
\hline No & 1.0000 & & & & & & & \\
\hline yes & -1.5812 & 0.4241 & 13.9019 & 1 & 0.0002 & 0.2057 & 0.0896 & 0.4724 \\
\hline \multicolumn{9}{|l|}{ Family size } \\
\hline Up to 6 members & 1.0000 & & & & & & & \\
\hline$>6$ members & 0.4223 & 0.2815 & 2.2504 & 1 & 0.1336 & 1.5254 & 0.8786 & 2.6486 \\
\hline \multicolumn{9}{|l|}{ Education level } \\
\hline Informal & 1.0000 & & & & & & & \\
\hline Formal & 0.7871 & 0.2780 & 8.0153 & 1 & 0.0046 & 2.1970 & 1.2740 & 3.7884 \\
\hline \multicolumn{9}{|l|}{ Monthly income } \\
\hline 451-1450 SDG & 0.4433 & 0.2633 & 2.8343 & 1 & 0.0923 & 1.5578 & 0.9298 & 2.6101 \\
\hline Constant & 0.6301 & 0.2294 & 7.5464 & 1 & 0.0060 & 1.8778 & & \\
\hline
\end{tabular}


Multivariate analysis revealed that knowledge of mothers about ITNs has significant association with age, household work and education. The analysis suggested that mothers aged 31 years or less were more likely to have knowledge about ITNs compared with mother with age more than 32 years [OR; 0.5174 (95\% CI: 0.2974-0.9001)]. Similarly, mothers had formal education were more likely to have knowledge about ITNs two times higher than those with informal education [OR; $2.2(95 \%$ CI: 1.274-3.788)]. In addition, mothers with working household were more likely to have knowledge about ITNs [OR; 0.21 (95\% CI: 0.08960.4724)] than those mothers with husbands not working. While no significant association was found between mothers knowledge and mother work, family size, and monthly income ( $p>0.05)$, Further details of analysis are presented in Table 3.

Table 4. Association between socio-demographic variables and attitudes and practices of mothers regarding ITNs.

\begin{tabular}{|c|c|c|c|c|c|c|c|c|}
\hline \multirow{2}{*}{ Variables } & \multicolumn{4}{|c|}{ Attitudes } & \multicolumn{4}{|l|}{ Practice } \\
\hline & B & Sig. & $\operatorname{Exp}(B)$ & 95.0\% C.I. for $\operatorname{EXP(B)}$ & B & Sig. & $\operatorname{Exp}(B)$ & $95.0 \%$ C.I. for $\operatorname{EXP}(B)$ \\
\hline \multicolumn{9}{|l|}{ Age } \\
\hline 31 years or less & 1.0000 & & & & 1.0000 & & & \\
\hline More than 32 years & -0.775 & 0.008 & 0.461 & $(0.2578-0.8232)$ & -0.5951 & 0.0335 & 0.5515 & $(0.3186-0.9547)$ \\
\hline \multicolumn{9}{|l|}{ Mother work } \\
\hline No & 1.000 & & & & 1.0000 & & & \\
\hline yes & -0.974 & 0.015 & 0.378 & $(0.1719-0.8296)$ & -0.2275 & 0.5064 & 0.7965 & $(0.4072-1.5582)$ \\
\hline \multicolumn{9}{|l|}{ Household work } \\
\hline No & 1.000 & & & & 1.0000 & & & \\
\hline yes & -1.220 & 0.001 & 0.295 & $(0.1423-0.6118)$ & 0.1884 & 0.6059 & 1.2073 & $(0.5903-2.4691)$ \\
\hline \multicolumn{9}{|l|}{ Family size } \\
\hline Up to 6 members & 1.000 & & & & 1.0000 & & & \\
\hline$>6$ members & 0.395 & 0.167 & 1.485 & $(0.8474-2.6019)$ & 0.3687 & 0.1874 & 1.4459 & $(0.8357-2.5017)$ \\
\hline \multicolumn{9}{|l|}{ Education level } \\
\hline Informal & 1.000 & & & & 1.0000 & & & \\
\hline Formal & 0.693 & 0.019 & 1.999 & $(1.1182-3.5731)$ & -0.2178 & 0.4284 & 0.8043 & $(0.4691-1.3789)$ \\
\hline \multicolumn{9}{|l|}{ Monthly income } \\
\hline Up to $450 \mathrm{SDG}$ & 1.000 & & & & 1.0000 & & & \\
\hline 451-1450 SDG & -0.687 & 0.013 & 0.503 & $(0.2922-0.8663)$ & 0.5265 & 0.0434 & 1.6929 & $(1.0158-2.8214)$ \\
\hline Constant & -0.734 & 0.001 & 0.480 & & 0.3597 & 0.0883 & 1.4329 & \\
\hline
\end{tabular}

$1=$ Reference group

Multivariate analysis illustrate that mothers attitude towards ITNs has significant association with age, mother work, household work, education and monthly income. We observed that mothers with age $<31$ years had positive attitudes towards ITNs [OR $=0.461 ; 95 \% \mathrm{CI}=(0.2578$ $0.8232)]$. In addition, mothers with formal education were more likely had positive attitude toward ITNs two time higher than those with informal education [OR; 1.99 (95\% CI: 1.1182-3.5731)]. As well mother with up to 450 SDG household monthly income more likely have a positive attitudes towards ITNs[OR; 0.503 (95\% CI: (0.2922-0.8663)] than mother with monthly income (451-1450 SDG). While no significant association was observed between mothers attitude and family size $[\mathrm{OR}=1.485 \mathrm{CI}=(0.8474-2.6019)]$.

With regard to mothers practices the results showed significant association with (451-1450 SDG) household monthly income were more likely to practice activities likes owing ITN, sleeping under a net, hang up the net before sun set, use ITN all over the year, use ITN for all family members, washing ITN periodically and re-treat the net two time higher than those with Up to 450 SDG household monthly income [OR; 1.69 (95\% CI: 1.0158-2.8214)]. While no significant association was observed between mothers practices regarding ITNs and age, mother work, household work, family size and education $(p>0.05)$. More details of analysis are presented in Table 4 .

\section{Discussion}

This study showed that more than half (55.9\%) of mothers had good knowledge regarding ITNs, which may motivate them to use ITNs more effectively [11]. In spite of fairly good knowledge about ITNs, the attitude and practice of mothers to ITNs was still poor. The $66.8 \%$ of mothers had negative attitude was recorded in this study which is slightly lesser than reported in Nigeria (70\%) [12].

The probable reasons for the poor attitude toward ITNs could be misunderstanding of its importance and lack of cultural exposure to the use of mosquito nets.

However $(66 \%)$ of mothers reported that they owned an ITN, only (27.8\%) reported always sleeping under it. Thus considerably lower than $80 \%$ of the targeted coverage of the Roll Back Malaria [13]. Moreover, this is higher than ITNs use rate in other malaria endemic countries, such as Iran (18.0\%), Southern Ethiopia 15.8\% [14], [3] and much lower than Sri Lanka (90\%) and India (79.2\%) [15], [16].

Regarding disparities between household possession of ITN and ITN use, this study showed that proportion of net 
use among mothers (27.8\%) and ownership (66.0\%) of households owning at least one net. Assessment surveys conducted in Africa showed similar disparities between household possession of ITN and ITN use [17]. Likewise, recent data showed that households owning an ITN increased up to $65 \%$ in one study, the use of ITNs among women was only $23 \%$ [18]. Despite a high coverage of ITN users remains less than that of ITN owners. These disparities might be due to many reasons hindering ITNS use likes lack of cultural exposure to the use of mosquito nets, negative perception such as ITN cause allergic, thermal stress, and difficulties in collecting and hanging ITNs every day.

Multivariate analysis revealed that knowledge of mothers about ITNs has significant association with age and education. The analysis suggested that younger mothers $\leq 31$ years were more likely to have knowledge about ITNs than the others ( $>32$ years). The majority of younger mothers $(67.3 \%)$ had formal education. This might have lead to an increased level of knowledge about ITNs, because the formal school curriculum might have sensitized them with many health education messages about prevention of diseases.

As well, mothers had formal education were more likely to have knowledge about ITNs two time higher than those with informal education. This finding is in agreement with recent study conducted in Iran by Hanafi et al., in 2011 who found that educational level is positively associated with knowledge of malaria [19]. Whereas in contrary with a previous study conducted in Nigeria by Charles et al., in 2017 who found that female education were not significantly associated with ITN knowledge, and usage [20].

Related to association between socio-demographic and mothers practices regarding ITNs, only association between income and practice is evident. Higher income group is more likely to practice than low income group. Previous study conducted by Michelle et al., 2005 in Mali how found that cost was the main factor. Similar results have been found in other studies [21], [22]. Moreover other study reported those who have better income were 1.8 times more likely utilize ITN than have less income[23]. This might be people with low income concerns about the cost of ITNs and absence of a sustainable mechanism for the distribution of ITNS. While no significant association was observed between mother's practices regarding ITNs and education. Njoroge et al., in 2009 highlighted the fact that high level of knowledge does not necessarily translate to use of appropriate interventions [24]. This is also similar with the findings of the studies in Kenya and Northern Ethiopia [25], [26]. Other studies showed that good knowledge is associated with poor practice [12]. Which is concordant with the findings of the study conducted by Tarfi et al. 2015 in Ethiopia who found that level of education was significant predictor of ITNs use. Another study in Iran showed that bed net use rate was positively associated with educational level of respondents [3], [19].

\section{Conclusions}

We conclude that the attitude and practice of mothers to
ITNs in this study was poor. In spite of fairly good knowledge of the benefits of ITNs. (66.0\%) mothers owned an ITN, only $(27.8 \%)$ reported always sleeping under it. This explain the disparities between mothers possession of ITN and ITN use. Multivariate analysis suggested that younger mothers $<31$ years were more likely to have knowledge about ITNs than the others ( $>32$ years). As well, mothers had formal education were more likely to have knowledge about ITNs, two time higher than those with informal education. However only association between income and practice is evident. Higher income group is more likely to practice than low income group. While no significant association was observed between mother's practices regarding ITNs and education.

\section{Recommendation}

The study reveals that mothers have adequate knowledge about ITNs and of the link between the use of ITN and malaria control. While attitude of mothers towards the use of ITNs was poor, so creating only the awareness is not enough. People should be motivated to create a culture and enhance their understanding towards practicing preventive measures against malaria, like use of ITN, environmental intervention and insecticide spray. This can be achieved through formal education. Involvement of formal education in malaria control has a critical role to play. Education System and the Malaria Control Programme in North Sudan should work closely, especially on malaria education for behavioural change. Furthermore the Health authority should enhance training of volunteers and local leaders towards proper utilization of ITNs.

\section{References}

[1] Rupashree Singh, Jamila Musa, Sanjay Singh, and Ukatu Victoria Ebere. Knowledge, Attitude and Practices on Malaria Among the Rural Communities in Aliero, Northern Nigeria. J Family Med Prim Care v.3(1); 2014 PMC400519R9

[2] WHO. World malaria report. Geneva, Switzerland: World Health Organization; 2015. http://www.who.int/malaria/publications/2015

[3] Terefe G. Fuge, Samuel Y. Ayanto, and Fiseha L. Gurmamo. Assessment of knowledge, attitude and practice about malaria and ITNs utilization among pregnant women in Shashogo District, Southern Ethiopia. Malar J. 2015; 14: 235.

[4] Federal ministry of health (2012). Malaria Indicator Survey Northern States of the Sudan

[5] Yousif M. Elmosaad, Magda Elhadi, Asif Khan, Elfatih M. Malik and Ilias Mahmud. Communication for behavioural impact in enhancing utilization of insecticide-treated bed nets among mothers of under-five children in rural North Sudan: an experimental study. Malar J (2016) 15:509

[6] Lengeler. C: (2004): Insecticide-treated bed nets and curtains for preventing malaria.1stedition, CD000363. Pg. 3,8, USA.

[7] Roll Back Malaria (RBM) (2005): Insecticide-treated mosquito nets, malaria matters vol 18 (5), Published by Jossey- Bass, USA. 
[8] Nevill C, Some E, Mung'ala V, Mutemi W, New L, Marsh K, Lengeler C, Snow R: Insecticide-treated bednets reduce mortality and severe morbidity from severe malaria among children on the Kenyan coast. Trop Med Int Health 1996, $1: 139-146$

[9] Alessandro U, Olaleye B, McGuire W, Langerock P, Bennett S, Aikins M, Thomson M, Cham M, Greenwood BM: Mortality and morbidity from malaria in Gambian children after introduction of an impregnated bednet programme. Lancet 1995, 346:462-467

[10] Michelle Rhee, Mahamadou Sissoko, Sharon Perry, Willi McFarland, Julie Parsonnet1 and Ogobara Doumbo. Use of insecticide-treated nets (ITNs) following a malaria education intervention in Piron, Mali: a control trial with systematic allocation of households. Malaria Journal 2005, 4:35 doi:10.1186/1475-2875-4-35

[11] Toe LP, Skovmand O, Dabire KR, Diabate A, Diallo Y, Guiguemde TR,Doannio JM, Akogbeto M, Baldet T, Gruenais ME: Decreased motivation in the use of insecticide-treated nets in a malaria endemic area in BurkinaFaso. Malar J. 2009, $8: 175$

[12] Runsewe-Abiodun, Iyabo $\mathrm{T}$ and Runsewe Olugbenga $\mathrm{O}$. Attitude and practice of pregnant women to use of insecticide treated nets in South-West Nigeria. African Journal of Pregnancy and Childbirth 2013, Vol. 1 (1), pp. 001-009

[13] WHO. World malaria report. Geneva, Switzerland: World Health Organization; 2010.

http://www.who.int/malaria/publications/2015

[14] Mussa Soleimani-Ahmadi, Hassan Vatandoost, Mehdi Zare, Ali Alizadeh and Mehrdad Salehi. Community knowledge and practices regarding malaria and long-lasting insecticidal nets during malaria elimination programme in an endemic area in Iran Malaria Journal 2014, 13:511

[15] Fernando SD, Abeyasinghe RR, Galappaththy GN, Gunawardena N, Ranasinghe AC, Rajapaksa LC: Sleeping arrangements under long-lasting impregnated mosquito nets: differences during low and high malaria transmission seasons. Trans R Soc Trop Med Hyg 2009, 103:1204-1210.

[16] Gunasekaran K, Sahu SS, Vijayakumar KN, Jambulingam P: Acceptability, willing to purchase and use long lasting insecticide treated mosquito nets in Orissa State, India. Acta Trop 2009, 112:149-155.

[17] Eisele TP, Keating J, Littrell M, Larsen D, Macintyre K: Assessment of insecticide-treated bednet use among children and pregnant women across 15 countries using standardized national surveys. Am J Trop Med Hyg 2009, 80:209-214.

[18] Hanson K, Marchant T, Nathan R, Mponda H, Jones C, et al. Household ownership and use of insecticide treated nets among target groups after implementation of a national voucher programme in the United Republic of Tanzania: plausibility study using three annual cross sectional household surveys. BMJ, 2009; 339: b2434.

[19] Hanafi-Bojd AA, Vatandoost H, Oshaghi MA, Eshraghian MR, Haghdoost AA, Abedi F, Zamani G, Sedaghat MM, Rashidian A, Madani AH, Raeisi A: Knowledge, attitudes and practices regarding malaria control in an endemic area of southern Iran. Southeast Asian J Trop Med Public Health 2011, 42:491-501.

[20] Charles Ibiene Tobin-West, Esther Njideka Kanu. Factors influencing the use of malaria prevention methods among women of reproductive age in peri-urban communities of Port Harcourt City, Nigeria. Nigerian Postgraduate Medical Journal 2017 23, (1) PP: 6-11

[21] Cham MK, Olaleye B, D'Alessandro U, Aikins M, Cham B, Maine N, Williams LA, Mills A, Greenwood BM: The impact of charging for insecticide on the Gambian National Impregnated Programme. Health Policy Plan 1997, 12:240247.

[22] Winch PJ, Makemba AM, Makame VR, Mfaume MS, Lynch MC, Premji C, Minjas JN, Shiff CJ: Social and cultural factors affecting rates of regular retreatment of mosquito nets with insecticide in Bagamoyo District, Tanzania. Trop Med Int Health 1997, 2:760-770.

[23] Yibeltal Berie, Kasahun Alemu, Alemayehu Belay, Zemichale Gizaw. Factors Affecting Utilization of Insecticide Treated Nets among People Living with HIV/Aids in Bahir Dar City, Northwest Ethiopia. Science Journal of Clinical Medicine. Vol. 2, No. 6, 2013, pp. 147-152.

[24] Njoroge FK, Kimani VN, Ongore D, \&Akwale W. S. Use of insecticide treated bed nets among pregnant women in Kilifi District, Kenya. East Afr Med J. 2009, 86 (7):314 - 22).

[25] Belay M, Deressa W. Use of insecticide treated nets by pregnant women and associated factors in a pre-dominantly rural population in northern Ethiopia. Trop Med Int Health. 2008; 13(10):1303-13.

[26] Zewdneh Tomass, Bereket Alemayehu, Meshesha Balkew and Dawit Leja. Knowledge, attitudes and practice of communities of Wolaita, Southern Ethiopia about long-lasting insecticidal nets and evaluation of net fabric integrity and insecticidal activity. Parasites \& Vectors J. 2016 :9:224.

[27] Yousif M. Elmosaad, Magda Elhadi, Ahmed Elnadif, Mustafa M. Mustafa, Ibrahim Alasqah. The Role of Health Promoters in Raising Mothers of Under-Five Children Knowledge, Attitude and Practices Regarding Malaria. Science Journal of Public Health. 2017; Vol. 5, No. 2, pp. 145-151.

[28] Runsewe-Abiodun, Iyabo T1and Runsewe Olugbenga O. Attitude and practice of pregnant women to use of insecticide treated nets in South-West Nigeria. African Journal of Pregnancy and Childbirth, 2013; Vol. 1 (1), pp. 001-009

[29] Michelle Rhee, Mahamadou Sissoko, Sharon Perry, Willi Mc Farland, Julie Parsonnet1 and Ogobara Doumbo. Use of insecticide-treated nets (ITNs) following a malaria education intervention in Piron, Mali: a control trial with systematic allocation of households. Malaria Journal 2005, 4:35.

[30] Ayodeji M. Adebayo, Oluwaseun O. Akinyemi and Eniola O. Cadmus. Knowledge of malaria prevention among pregnant women and female caregivers of under-five children in rural southwest Nigeria. Peer J. 2015; 3:792.

[31] Federal Ministry of Health, National Malaria Control Program, North Sudan, annual malaria report 2015. 